\title{
Study protocol: differential effects of diet and physical activity based interventions in pregnancy on maternal and fetal outcomes-individual patient data (IPD) meta-analysis and health economic evaluation
}

\author{
Anneloes E Ruifrok ${ }^{1,2}$, Ewelina Rogozinska ${ }^{3,5}$, Mireille NM van Poppel ${ }^{4}$, Girish Rayanagoudar ${ }^{3}$, Sally Kerry ${ }^{5}$, \\ Christianne JM de Groot ${ }^{2}$, SeonAe Yeo ${ }^{6}$, Emma Molyneaux ${ }^{7}$, Fionnuala M McAuliffe ${ }^{8}$, Lucilla Poston', \\ Tracy Roberts $^{10}$, Richard D Riley ${ }^{11^{*}}$, Arri Coomarasamy ${ }^{12}$, Khalid Khan ${ }^{3,5}$, Ben Willem Mol ${ }^{13}$, Shakila Thangaratinam ${ }^{3,5}$ \\ for the i-WIP (International Weight Management in Pregnancy) Collaborative Group
}

\begin{abstract}
Background: Pregnant women who gain excess weight are at risk of complications during pregnancy and in the long term. Interventions based on diet and physical activity minimise gestational weight gain with varied effect on clinical outcomes. The effect of interventions on varied groups of women based on body mass index, age, ethnicity, socioeconomic status, parity, and underlying medical conditions is not clear. Our individual patient data (IPD) meta-analysis of randomised trials will assess the differential effect of diet- and physical activity-based interventions on maternal weight gain and pregnancy outcomes in clinically relevant subgroups of women.

Methods/design: Randomised trials on diet and physical activity in pregnancy will be identified by searching the following databases: MEDLINE, EMBASE, BIOSIS, LILACS, Pascal, Science Citation Index, Cochrane Database of Systematic Reviews, Cochrane Central Register of Controlled Trials, Database of Abstracts of Reviews of Effects, and Health Technology Assessment Database. Primary researchers of the identified trials are invited to join the International Weight Management in Pregnancy Collaborative Network and share their individual patient data. We will reanalyse each study separately and confirm the findings with the original authors. Then, for each intervention type and outcome, we will perform as appropriate either a one-step or a two-step IPD meta-analysis to obtain summary estimates of effects and $95 \%$ confidence intervals, for all women combined and for each subgroup of interest. The primary outcomes are gestational weight gain and composite adverse maternal and fetal outcomes. The difference in effects between subgroups will be estimated and between-study heterogeneity suitably quantified and explored. The potential for publication bias and availability bias in the IPD obtained will be investigated. We will conduct a model-based economic evaluation to assess the cost effectiveness of the interventions to manage weight gain in pregnancy and undertake a value of information analysis to inform future research.
\end{abstract}

Systematic review registration: PROSPERO 2013:CRD42013003804

Keywords: Individual patient data meta-analysis, Diet and physical activity, Pregnancy, Weight gain

\footnotetext{
*Correspondence: r.d.riley@bham.ac.uk

${ }^{11}$ School of Health and Population Sciences, College of Medical and Dental Sciences, University of Birmingham, Edgbaston, Birmingham B15 2TT, UK Full list of author information is available at the end of the article
} 


\section{Background}

Excessive weight gain in pregnancy is associated with maternal and fetal complications such as pre-eclampsia, gestational diabetes, caesarean section, large for gestational age babies [1-8], and postpartum weight retention $[9,10]$. It is a risk factor for maternal and childhood obesity in the long term $[5,9,11]$, resulting in significant burden to the health care systems globally [9,10,12-17]. In the UK, obesity costs the National Health Service (NHS) around $£ 4$ billion a year and the economy a further $£ 16$ billion in indirect costs $[18,19]$. Reducing excessive weight gain in pregnancy by effective weight management programmes could lead to significant societal advantages in terms of health and costs.

In the antenatal period, women are in regular contact with health professionals and are highly motivated to make changes that may improve their pregnancy outcomes [20]. Our study-level meta-analysis of 44 randomised trials showed that dietary and lifestyle interventions were effective in reducing weight gain in pregnancy and reduced risk of adverse outcomes [21]. We were restricted by unexplained heterogeneity of effects and paucity of published detail from making firm recommendations for clinical practice, especially for pregnancy outcomes. Importantly, we were unable to ascertain if the intervention had a differential beneficial effect on particular subgroups of women.

The only guidance on weight gain recommendations in pregnancy is by the Institute of Medicine (IOM) in the US, which is based on observational evidence. The UK and other European policy makers do not recommend specific weight gain targets in pregnancy due to the absence of robust evidence. The Public Health Interventions Advisory Committee (PHIAC) in the UK has prioritised the need for research to identify the most effective and cost-effective ways of helping women to manage their weight during pregnancy, including women who are obese, those who are under 18 and those from disadvantaged, low income and minority ethnic groups [22]. Additionally, they highlighted the need to ascertain whether adherence to IOM recommendations on gestational weight gain improves obstetric outcomes, especially in minority groups and teenagers.

We plan to undertake an individual patient data (IPD) meta-analysis [23] to robustly address the above questions on the effect of weight management interventions in women stratified by BMI, ethnicity, socioeconomic status and teenage pregnancies by obtaining raw patientlevel data for synthesis across trials.

\section{Objectives}

The primary objective of this IPD meta-analysis is to determine the differential effects of weight management interventions in pregnancy on maternal weight gain and composite adverse maternal and fetal outcomes in women according to their (i) body mass index (BMI), (ii) age, (iii) ethnicity, (iv) parity, and (v) underlying medical conditions.

The secondary objectives are to:

i. Validate weight change as an outcome measure by quantifying the relationship between the amount of weight gained in pregnancy and the risk of adverse maternal and fetal outcomes for normal weight (BMI 18.5-24.9 kg/m²), overweight (BMI $\left.25-29.9 \mathrm{~kg} / \mathrm{m}^{2}\right)$ and obese (BMI $\geq 30 \mathrm{~kg} / \mathrm{m}^{2}$ ) women

ii. Assess if adherence in pregnancy to IOM weight gain recommendations minimises adverse pregnancy outcomes in normal weight, overweight and obese women

iii. Identify the prognostic factors for gestational weight gain based on patient characteristics such as prepregnancy BMI, age, ethnicity, socioeconomic status, parity, ethnicity, smoking, diet and lifestyle

iv. Undertake network meta-analysis to produce a rank order of interventions

v. Assess the cost effectiveness of the various interventions in pregnancy using model-based full economic evaluation with value of information (VOI) analysis

\section{Methods/design}

Our IPD meta-analytical approach will follow existing guidelines, and our output will comply with the PRISMA statement and adhere to recent reporting guidelines for IPD meta-analysis.

\section{Search strategy}

We will update the literature search to identify new trials published since the completion of our systematic review (HTA No. 09/27/06) on effects of weight management interventions in pregnancy [21]. The following databases will be searched: MEDLINE, EMBASE, BIOSIS, LILACS, Pascal, Science Citation Index, Cochrane Database of Systematic Reviews (CDSR), Cochrane Central Register of Controlled Trials (CENTRAL), Database of Abstracts of Reviews of Effects (DARE) and Health Technology Assessment Database (HTA). Other relevant databases including the Inside Conferences, Systems for Information in Grey Literature (SIGLE), Dissertation Abstracts, and Clinical Trials.gov will be searched. Internet searches will include specialist search gateways (such as OMNI: http://omni.ac. uk), general search engines (such as Google: https://www. google.co.uk), and meta-search engines (such as Copernic: http://www.copernic.com). In addition, information on studies in progress, unpublished research, research reported in the grey literature, and details from commercial 
providers will be sought. Language restrictions will not be applied. The search will be updated 1 year before the end of the project to avoid missing recently published studies.

\section{Establishment of the International Weight Management in Pregnancy IPD Collaboration}

We contacted researchers who have published trials on weight management interventions in pregnancy and established the International Weight Management in Pregnancy (i-WIP) IPD Collaborative Network [21]. There has been an overwhelming interest for a joint endeavour in this field. The network, supported by WHO (World Health Organization), is a global effort in bringing together researchers, clinicians and epidemiologists from 14 countries (https://kamolo.org.ar/ iwipipd) Thirty-six collaborators have joined the network to date providing access to anonymised individual data of 9,344 women (Table 1).

\section{Inclusion and exclusion criteria}

Randomised controlled trials evaluating diet- and physical activity-based interventions in pregnancy compared to normal antenatal care are eligible for inclusion. Underweight women (BMI $<18.5 \mathrm{~kg} / \mathrm{m}^{2}$ ) and women with contra-indications to limit gestational weight gain will be excluded. The interventions include those that are based on diet, physical activity, or a mixed approach comprising diet and physical activity with or without behavioural modification techniques. Studies assessing weight-reducing drugs or surgical interventions will not be included.

\section{Outcome measures}

The primary outcome measures are (i) maternal weight gain in pregnancy and (ii) composite adverse maternal and fetal outcomes. Gestational weight gain is defined as the change in weight from the first scheduled visit to the weight measured before delivery. The composite outcome includes those components that are critically important to clinical practice and whose underlying biology is similar [24]. The individual components were defined according to NICE guidelines $[25,26]$ and identified by a four-round Delphi survey. The first two rounds of the survey identified the clinically important outcomes with input from experts [27]. The subsequent two rounds of the Delphi survey were completed by i-WIP collaborators to ensure that the outcomes were clinically relevant, of equal importance, occur with similar frequency and have the same direction of effect with the intervention (Table 2). We will include in our analysis those components for which robust data is available across the individual studies.

\section{Study quality assessment and data collection}

A bespoke database will be set up and authors will be allowed to supply data in whatever way convenient to them. We will consider all recorded variables, even those not reported in the published studies. The quality of each trial will be assessed $[28,29]$ to evaluate the integrity of the randomisation and follow-up procedure. We will evaluate the risk of bias in individual studies by considering six items used in the Cochrane risk of bias tool: sequence generation, allocation concealment, blinding, incomplete outcome data, selective outcome reporting, and other potential sources of bias.

\section{Sample size considerations}

Although no formal sample size requirements are necessary for the meta-analysis, we have considered the potential power of our IPD meta-analysis in comparison to single trials in this field to detect clinically important effects in each subgroup separately (Table 3 ). All calculations relate to a type I error of $5 \%$, a power of $80 \%$ and a loss to follow-up of $5 \%$. We chose a reduction of $2.5 \mathrm{~kg}$ in gestational weight gain as the minimally important difference (MID), since it was associated with improvement in obstetric outcomes [12]. Our sample size will be over 9,000 women. For maternal weight gain, the sample size required for all subgroups is 300 or less. Given the large sample size available, it is highly likely that the study is powered to detect important differences between subgroups (that is, to identify genuine factors that modify treatment effect). This will allow us to detect interaction terms as small as about $30 \%$ of the size of the overall treatment effect. So, if the overall intervention effect is a reduction in weight gain of $2.5 \mathrm{~kg}$, then our IPD meta-analysis will have $80 \%$ power to detect an interaction term of about $2.5 \times 0.3=0.75$ or above (e.g. a difference in intervention effect of $0.75 \mathrm{~kg}$ between obese and normal weight women).

For the composite outcome of adverse maternal and fetal outcomes, we calculated the sample size needed to detect an intervention effect of a $30 \%$ reduction in adverse pregnancy outcome. Our estimates of the standard deviation (SD) of the control group and the risk of composite pregnancy outcome were obtained from the data of primary studies included in our systematic review. The largest sample size required is 2,330 for the adverse pregnancy outcome in the normal BMI group. Of our 5,000 women, we expect over half to be in this normal category. For overweight and obese women, the sample size required for the adverse pregnancy outcome is 1,290 and 770 respectively (Table 4 ).

Table 1 shows a comparison of existing evidence on effectiveness of weight management interventions in pregnancy and the proposed IPD meta-analysis. 
Table 1 Studies with provisional support and consideration to share individual patient data

\begin{tabular}{|c|c|c|c|c|c|}
\hline \multirow[t]{2}{*}{ Study year } & \multirow[t]{2}{*}{ Country } & \multirow[t]{2}{*}{ Study characteristics } & \multicolumn{2}{|l|}{ Outcomes } & \multirow{2}{*}{$\begin{array}{l}\text { Sample } \\
\text { size }\end{array}$} \\
\hline & & & Maternal & Fetal & \\
\hline Althuizen 2012 & Netherlands & $\begin{array}{l}\text { Ethnically diverse; no BMI restrictions; age, nr; GA } \\
\text { at inclusion, <14 weeks; glucose status, nr; other } \\
\text { risk factors, nr }\end{array}$ & $\begin{array}{l}\text { GWG, GDM, } \\
\text { preterm delivery, } \\
\text { CS }\end{array}$ & Birth weight, macrosomia & 269 \\
\hline Barakat 2009 & Spain & $\begin{array}{l}\text { Caucasian; BMI restrictions, nr; age, } 25-35 \text { years; } \\
\text { GA at inclusion, nr (total at least } 26 \text { weeks } \\
\text { intervention); glucose status, nr; no known } \\
\text { pre-existing health problems }\end{array}$ & $\begin{array}{l}\text { GWG, GA, preterm } \\
\text { delivery }\end{array}$ & $\begin{array}{l}\text { Birth weight, LGA, SGA, AS, } \\
\text { macrosomia }(>4,000 \mathrm{~g})\end{array}$ & 142 \\
\hline Barakat 2011 & Spain & $\begin{array}{l}\text { Spanish (White); BMI restrictions, nr; age, } 23-38 \\
\text { years; GA at inclusion, first prenatal visit; glucose } \\
\text { status, nr; no known pre-existing health problems }\end{array}$ & $\begin{array}{l}\text { GWG, GA CS, } \\
\text { vaginal delivery }\end{array}$ & Birth weight, AS & 80 \\
\hline Barakat 2013 & Spain & $\begin{array}{l}\text { Caucasian; no BMl restrictions; age, nr; GA at } \\
\text { inclusion, <10 weeks; glucose status, nr; no } \\
\text { known pre-existing health problems }\end{array}$ & $\begin{array}{l}\text { GWG, GA, GDM, } \\
\text { PIH, preterm } \\
\text { delivery }\end{array}$ & Birth weight, AS & 765 \\
\hline Bogaerts 2012 & Belgium & $\begin{array}{l}\text { Ethnically diverse; } \mathrm{BMl}, \geq 29 \mathrm{~kg} / \mathrm{m}^{2} \text {; age, } \mathrm{nr} ; \mathrm{GA} \\
\text { at inclusion, }<15 \text { weeks; nondiabetic; Other risk } \\
\text { factors, } \mathrm{nr}\end{array}$ & $\begin{array}{l}\mathrm{GWG}, \mathrm{GA}, \mathrm{PE}, \mathrm{PIH}, \\
\mathrm{GDM}, \mathrm{IOL}, \mathrm{CS} \\
\text { vaginal delivery }\end{array}$ & Birth weight, AS & 197 \\
\hline Cavalcante 2009 & Brazil & $\begin{array}{l}\text { Race, nr; no morbid obesity; age restrictions, nr; } \\
\text { GA at inclusion, } 16-20 \text { weeks; glucose status, nr; } \\
\text { no known pre-existing health problems }\end{array}$ & $\begin{array}{l}\text { GWG, preterm } \\
\text { delivery }\end{array}$ & Birth weight & 71 \\
\hline Clapp 1997 & USA & $\begin{array}{l}\text { Race, nr; no morbid obesity; age restrictions, nr; } \\
\text { GA at inclusion, } 8 \text { weeks; glucose status, nr; no } \\
\text { known pre-existing health problems }\end{array}$ & GWG & Birth weight & 51 \\
\hline Clapp 2000 & USA & $\begin{array}{l}\text { Race, nr; no morbid obesity; age restrictions, nr; } \\
\text { GA at inclusion, } 8 \text { weeks; glucose status, nr; no } \\
\text { known pre-existing health problems }\end{array}$ & GWG, GA & Birth weight & 12 \\
\hline Dodd 2014 & Australia & $\begin{array}{l}\text { Race, } \mathrm{nr} ; \mathrm{BMl}, \geq 25 \mathrm{~kg} / \mathrm{m}^{2} \text {; age restrictions, } \mathrm{nr} ; \mathrm{GA} \\
\text { at inclusion, }<20 \text { weeks; nondiabetic; other risk } \\
\text { factors, } \mathrm{nr}\end{array}$ & $\begin{array}{l}\mathrm{PE}, \mathrm{PIH}, \mathrm{GDM}, \mathrm{IOL}, \\
\text { CS, preterm } \\
\text { delivery }\end{array}$ & $\begin{array}{l}\text { LGA, macrosomia }(>4,000 \mathrm{~g}) \text {, } \\
\text { hypoglycaemia, shoulder dystocia, } \\
\text { admission to NICU }\end{array}$ & 1,582 \\
\hline El Beltagy 2013 & Egypt & $\begin{array}{l}\text { Race, } \mathrm{nr} ; \mathrm{BMI} \text {, obese; age restrictions, } \mathrm{nr} ; \mathrm{GA} \text { at } \\
\text { inclusion, first antenatal visit; glucose status, nr; } \\
\text { other risk factors, nr }\end{array}$ & GWG, GDM & Birth weight, macrosomia & 100 \\
\hline Grant 2013 & Canada & $\begin{array}{l}\text { Race, predominantly non-Caucasian; BMI } \\
\text { restrictions, nr; age, >18 years, GA at inclusion, } \\
\text { nr; glucose status, impaired glucose tolerance or } \\
\text { GDM; no known pre-existing health problems }\end{array}$ & GWG & Birth weight, macrosomia & 47 \\
\hline Guelinckx 2010 & Belgium & $\begin{array}{l}\text { Caucasian; BMI, } \geq 29 \mathrm{~kg} / \mathrm{m}^{2} ; \text { age restrictions, } \mathrm{nr} ; \\
\mathrm{GA} \text { at inclusion, }<15 \text { weeks; nondiabetic; no } \\
\text { known pre-existing health problems }\end{array}$ & $\begin{array}{l}\text { GWG, GA, PE, PIH, } \\
I O L, C S\end{array}$ & Birth weight, LGA & 85 \\
\hline Haakstad 2011 & Norway & $\begin{array}{l}\text { Race, } \mathrm{nr} ; \mathrm{BMI} \text { restrictions, } \mathrm{nr} \text {; age restrictions, } \mathrm{nr} ; \\
\mathrm{GA} \text { at inclusion, <24 weeks; glucose status, } \mathrm{nr} ; \\
\text { no known pre-existing health problems }\end{array}$ & GWG & & 105 \\
\hline Hui 2006 & Canada & $\begin{array}{l}\text { Ethnically diverse; BMI restrictions, nr; age } \\
\text { restrictions, nr; GA at inclusion, <26 weeks; } \\
\text { nondiabetic; no known pre-existing health } \\
\text { problems }\end{array}$ & GWG, GA, GDM & Birth weight, LGA & 45 \\
\hline Hui 2011 & Canada & $\begin{array}{l}\text { Race, } \mathrm{nr} \text {; BMI restrictions, } \mathrm{nr} \text {; age restrictions, } \mathrm{nr} \text {; } \\
\text { GA at inclusion, } 20-26 \text { weeks; nondiabetic; no } \\
\text { known pre-existing health problems }\end{array}$ & $\begin{array}{l}\text { GWG, GA, GDM, } \\
\text { CS }\end{array}$ & Birth weight, LGA & 224 \\
\hline Jackson 2010 & USA & $\begin{array}{l}\text { Ethnically diverse; BMl restrictions, } \mathrm{nr} \text {; } \\
\text { age, }>18 \text { years; GA at inclusion, }<26 \text { weeks; } \\
\text { glucose status, nr; other risk factors, } \mathrm{nr}\end{array}$ & GWG & & 321 \\
\hline Jeffries 2009 & Australia & $\begin{array}{l}\text { Race, } \mathrm{nr} \text {; BMI restrictions, none; age, }>18 \text { to } \\
<45 \text { years, GA at inclusion, }<14 \text { weeks; } \\
\text { nondiabetic; other risk factors, } \mathrm{nr}\end{array}$ & $\begin{array}{l}\text { GWG, PE, PIH, } \\
\text { GDM, preterm } \\
\text { delivery, CS }\end{array}$ & $\begin{array}{l}\text { Birth weight, LGA, SGA, } \\
\text { hypoglycaemia, shoulder dystocia }\end{array}$ & 236 \\
\hline Khaledan 2010 & Iran & $\begin{array}{l}\text { Race, nr; BMI restrictions, nr; age restrictions, } \mathrm{nr} \text {; } \\
\text { GA at inclusion, } 24-32 \text { weeks; no diabetes } \\
\text { mellitus type } 1 \text { (DM1) with poor control; no } \\
\text { known pre-existing health problems }\end{array}$ & GWG, GA, CS & Birth weight & 39 \\
\hline
\end{tabular}


Table 1 Studies with provisional support and consideration to share individual patient data (Continued)

\begin{tabular}{|c|c|c|c|c|c|}
\hline Khoury 2005 & Norway & $\begin{array}{l}\text { Caucasian; BMI, } 19-32 \mathrm{~kg} / \mathrm{m}^{2} \text {; age, } 21-38 \text { years; } \\
\text { GA at inclusion, } 17-20 \text { weeks; nondiabetic; no } \\
\text { known pre-existing health problems }\end{array}$ & $\begin{array}{l}\text { GWG, PE, preterm } \\
\text { delivery }\end{array}$ & $\begin{array}{l}\text { Birth weight, SGA, intra-uterine } \\
\text { death }\end{array}$ & 290 \\
\hline Luoto 2011 & Finland & $\begin{array}{l}\text { Race, } \mathrm{nr} ; \mathrm{BMI},>17 \mathrm{~kg} / \mathrm{m}^{2} \text {; age, }>18 \text { years; GA at } \\
\text { inclusion, } 8-12 \text { weeks; nondiabetic; no known } \\
\text { pre-existing health problems }\end{array}$ & $\begin{array}{l}\text { GWG, GA, PE, } \\
\text { GDM }\end{array}$ & Birth weight, LGA, SGA & 399 \\
\hline Nascimento 2011 & Brazil & $\begin{array}{l}\text { Race, nr; BMI, }>26 \mathrm{~kg} / \mathrm{m}^{2} \text {; age }>18 \text { years; GA at } \\
\text { inclusion, } 14-24 \text { weeks; nondiabetic; no known } \\
\text { pre-existing health problems }\end{array}$ & $\begin{array}{l}\text { GWG, PIH, GDM, } \\
\text { CS }\end{array}$ & Birth weight, AS, LGA, SGA & 82 \\
\hline Ong 2009 & Australia & $\begin{array}{l}\text { Race, nr; obese; age restrictions, nr; GA at } \\
\text { inclusion, } 18 \text { weeks; nondiabetic; other risk } \\
\text { factors, nr }\end{array}$ & GWG & & 12 \\
\hline Oostdam 2012 & Netherlands & $\begin{array}{l}\text { Ethnically diverse; BMI, } \geq 25.0 \mathrm{~kg} / \mathrm{m}^{2} \text {; age, } \\
>18 \text { years; GA at inclusion, }<20 \text { weeks; } \\
\text { nondiabetic; no known pre-existing health } \\
\text { problems }\end{array}$ & GWG, GDM & Birth weight & 124 \\
\hline Phelan 2011 & USA & $\begin{array}{l}\text { Ethnically diverse; BMI, } \geq 19.8-26.0 \mathrm{~kg} / \mathrm{m}^{2} \text {; age } \\
\text { >18 years; GA at inclusion, } 10-16 \text { weeks; glucose } \\
\text { status, nr; no known pre-existing health problems }\end{array}$ & $\begin{array}{l}\text { GWG, GA, PE, PIH, } \\
\text { GDM, preterm } \\
\text { delivery, CS }\end{array}$ & $\begin{array}{l}\text { Birth weight, macrosomia, birth } \\
\text { weight }<2,500 \mathrm{~g}\end{array}$ & 401 \\
\hline Poston 2013 & UK & $\begin{array}{l}\text { Race, } \mathrm{nr} ; \mathrm{BMI}, \geq 30 \mathrm{~kg} / \mathrm{m}^{2} \text {; age restrictions, } \mathrm{nr} ; \mathrm{GA} \\
\text { at inclusion, }>15^{+0} \text { weeks and }<17^{+6} \text {; nondiabetic; } \\
\text { no known pre-existing health problems }\end{array}$ & $\begin{array}{l}\text { GA, GWG, PE, } \\
\text { GDM, mode of } \\
\text { delivery }\end{array}$ & $\begin{array}{l}\text { Birth weight, macrosomia, still } \\
\text { birth }\end{array}$ & 183 \\
\hline Prevedel 2003 & Brazil & $\begin{array}{l}\text { Race, nr; BMI restrictions, nr; age restrictions, nr } \\
\text { (primiparous or adolescents); GA at inclusion, } \\
\text { 16-20 weeks; glucose status, nr; no known } \\
\text { pre-existing health problems }\end{array}$ & $\begin{array}{l}\text { GWG, preterm } \\
\text { delivery }\end{array}$ & Birth weight, SGA & 132 \\
\hline Rauh 2013 & Germany & $\begin{array}{l}\text { Race, } \mathrm{nr} ; \mathrm{BMI}, \geq 18.5 \mathrm{~kg} / \mathrm{m}^{2} \text {; age, } \geq 18 \text { years; GA } \\
\text { at inclusion, }<18 \text { weeks; nondiabetic; no known } \\
\text { pre-existing health problems }\end{array}$ & $\begin{array}{l}\text { GWG, GDM, IOL, } \\
\mathrm{CS} \text {, preterm } \\
\text { delivery }\end{array}$ & LGA, SGA & 250 \\
\hline Sagedal 2014 & Norway & $\begin{array}{l}\text { Race, } \mathrm{nr} ; \mathrm{BMI}, \geq 19 \mathrm{~kg} / \mathrm{m}^{2} \text {; age, } \geq 18 \text { years; GA } \\
\text { at inclusion, }<20 \text { weeks; nondiabetic; no known } \\
\text { pre-existing health problems }\end{array}$ & GWG, GDM, CS & LGA & 600 \\
\hline Stafne 2012 & Norway & $\begin{array}{l}\text { White; no BMI restrictions; age, }>18 \text { years; GA at } \\
\text { inclusion, } 18-22 \text { weeks; nondiabetic; no known } \\
\text { pre-existing health problems }\end{array}$ & $\begin{array}{l}\text { GA, PE, PIH, GDM, } \\
\text { CS }\end{array}$ & $\begin{array}{l}\text { Birth weight, AS, LGA, admission } \\
\text { to NICU }\end{array}$ & 124 \\
\hline Vesco 2013 & USA & $\begin{array}{l}\text { Race, } \mathrm{nr} ; \mathrm{BMI}, \geq 30 \mathrm{~kg} / \mathrm{m}^{2} \text {; age, } \mathrm{nr} ; \mathrm{GA} \text { at } \\
\text { inclusion, }<20 \text { weeks; nondiabetic; no known } \\
\text { pre-existing health problems }\end{array}$ & $\begin{array}{l}\text { GWG, GA, PE, PIH, } \\
\text { GDM, CS, preterm } \\
\text { delivery }\end{array}$ & $\begin{array}{l}\text { Birth weight, LGA, SGA, } \\
\text { macrosomia }(4,000 \mathrm{~g})\end{array}$ & 114 \\
\hline Vinter 2011 & Denmark & $\begin{array}{l}\text { Caucasian; BMI, } 30-45 \mathrm{~kg} / \mathrm{m}^{2} \text {; age, } 18-40 \text { years; } \\
\text { GA at inclusion, } 10-14 \text { weeks; nondiabetic; no } \\
\text { known pre-existing health problems }\end{array}$ & $\begin{array}{l}\text { GWG, PE, PIH, } \\
\text { GDM, CS }\end{array}$ & LGA, admission to NICU & 855 \\
\hline Vitolo 2011 & Brazil & $\begin{array}{l}\text { Race, nr; BMI restrictions, none; age, <35 years; } \\
\text { GA at inclusion, 10-29 weeks; nondiabetic; no } \\
\text { known pre-existing health problems }\end{array}$ & $\begin{array}{l}\text { GWG, PE, PIH, } \\
\text { GDM, preterm } \\
\text { birth }\end{array}$ & Birth weight & 315 \\
\hline Walsch 2012 & Ireland & $\begin{array}{l}\text { Race, nr; BMI restrictions, nr; age, >18 years; GA } \\
\text { at inclusion, < } 18 \text { weeks; nondiabetic; no known } \\
\text { pre-existing health problems }\end{array}$ & $\begin{array}{l}\text { GWG, GA, preterm } \\
\text { delivery, IOL, CS }\end{array}$ & Birth weight, macrosomia & 304 \\
\hline Wolff 2008 & Denmark & $\begin{array}{l}\text { Caucasian; BMI, } \geq 30 \mathrm{~kg} / \mathrm{m}^{2} \text {; age, }>18 \\
\text { to }<45 \text { years; GA at inclusion, }<18 \text { weeks; } \\
\text { nondiabetic; no known pre-existing health } \\
\text { problems }\end{array}$ & $\begin{array}{l}\text { GWG PE, PIH, } \\
\text { GDM , CS }\end{array}$ & Birth weight & 800 \\
\hline Yeo 2012 & USA & $\begin{array}{l}\text { Ethnically diverse; BMI, }>19.8 \mathrm{~kg} / \mathrm{m}^{2} \text {; no age } \\
\text { restrictions; GA at inclusion, } 18 \text { weeks; } \\
\text { nondiabetic; no known pre-existing health } \\
\text { problems }\end{array}$ & GWG, PE, PIH & Birth weight & 17 \\
\hline
\end{tabular}

AS Apgar score, CS caesarean section, GA gestational age, GDM gestational diabetes mellitus, GWG gestational weight gain, IOL induction of labour, LGA large for gestational age, NICU Neonatal Intensive Care Unit, $n r$ not reported, $P E$ pre-eclampsia, $P I H$ pregnancy-induced hypertension, $R D S$ respiratory distress syndrome, SGA small for gestational age. 
Table 2 Critically important maternal and fetal outcomes in the IPD meta-analysis of weight management interventions identified by the Delphi survey

\begin{tabular}{ll}
\hline Maternal outcomes & Fetal outcomes \\
\hline Pre-eclampsia & Intrauterine death \\
Pregnancy induced hypertension & Small for gestational age \\
Gestational diabetes mellitus & Large for gestational age \\
Preterm delivery & Admission to NICU \\
Caesarean section & Shoulder dystocia \\
Thromboembolism & $>1$ perinatal complication \\
Admission to high dependency unit/ & Birth trauma \\
intensive treatment unit & \\
Weight gain in pregnancy & Long-term neurological sequelae \\
& Long-term metabolic sequelae \\
\hline
\end{tabular}

\section{Data analysis}

Summarising the overall effect of weight management interventions

First, we will summarise the overall effect of each intervention (in relation to each outcome) across the entire set of available patient data. Meta-analyses of the effectiveness of weight management interventions in pregnancy will be performed for the weight-related and composite adverse maternal and fetal outcomes. We will include all patients ever randomised and will base our analysis on the intention to treat principle. Women with glucose intolerance will be excluded in the analysis of composite adverse pregnancy outcomes, as gestational diabetes is one of the components of the composite outcome.

All studies will be reanalysed separately and the original authors asked to confirm the individual study results, and any discrepancies will be resolved. Then, for each intervention type and outcome separately, we will perform either a one-step or a two-step IPD meta-analysis to obtain the pooled intervention effect. The one-step approach analyses the IPD from all studies simultaneously, whilst accounting for the clustering of patients within studies. In contrast, the two-step approach first estimates the intervention effect from the IPD in each study separately and then pools them using a conventional meta-analysis of the intervention effect estimates obtained. One-step and two-step meta-analyses usually give similar results but, where possible, will undertake both to ensure that conclusions remain robust to the choice of method $[23,30]$.

Given the heterogeneity identified in our previous review [21], we also expect to observe significant heterogeneity in the IPD meta-analysis. Thus, we will use a random effects meta-analysis approach, which allows for between-study heterogeneity in intervention effect. Heterogeneity will be summarised using the I-squared statistic (which provides the proportion of total variability that is due to between-study heterogeneity) and the estimated between-study variance ('tau-squared'), obtained using restricted maximum likelihood estimation.

For continuous outcomes, we will aim to synthesise mean differences (potentially standardised if outcome scales differ substantially) and adjust for baseline values using analysis of covariance, as recommended [31]. For binary outcomes, we will aim to synthesise relative risks or odds ratios, with the binomial nature suitably modelled using, for example, a one-step logistic regression adjusting for clustering. For any time-to-event outcome, we will aim to fit a Cox regression model (after checking for proportional hazards) in each study and then synthesise the estimated hazard ratios obtained. At the study-

Table 3 Comparison of existing evidence on effectiveness of weight management interventions and the proposed IPD meta-analysis

\begin{tabular}{|c|c|c|c|}
\hline Characteristics & $\begin{array}{l}\text { Existing systematic } \\
\text { reviews }\end{array}$ & $\begin{array}{l}\text { Published and } \\
\text { ongoing primary } \\
\text { studies }\end{array}$ & $\begin{array}{l}\text { Proposed IPD } \\
\text { meta-analysis }\end{array}$ \\
\hline Consistent inclusion and exclusion criteria e.g. BMI, risk status & $x$ & $\sqrt{ }$ & $\sqrt{ }$ \\
\hline $\begin{array}{l}\text { Assessment of effect of prognostic factors on treatment effect e.g. diabetic status, } \\
\text { chronic hypertension }\end{array}$ & $x$ & $\sqrt{ }$ & $\sqrt{ }$ \\
\hline Missing data observed and accounted at individual level & $x$ & $\sqrt{ }$ & $\sqrt{ }$ \\
\hline All critically important maternal and fetal outcomes considered & $\sqrt{ }$ & $x$ & $\sqrt{ }$ \\
\hline $\begin{array}{l}\text { Potential for sufficient power to assess for differential treatment effect across groups } \\
\text { e.g. BMI, ethnicity, race, parity }\end{array}$ & $x$ & $x$ & $\sqrt{ }$ \\
\hline Standardisation of statistical analysis across studies & $x$ & N/A & $\sqrt{ }$ \\
\hline $\begin{array}{l}\text { Correlation between multiple end points accounted e.g. each participant providing } \\
\text { data on gestational weight gain in various trimesters and weight retention postpartum }\end{array}$ & $x$ & $\sqrt{ }$ & $\sqrt{ }$ \\
\hline $\begin{array}{l}\text { Up to date follow-up information, potentially longer than that used in the original } \\
\text { study publication }\end{array}$ & $x$ & $x$ & $\sqrt{ }$ \\
\hline
\end{tabular}


Table 4 Sample size estimations evaluating the effect of weight management interventions

\begin{tabular}{|c|c|c|c|c|c|}
\hline Subgroups & & Control group SD & $\begin{array}{l}\text { Sample size required to } \\
\text { detect a } 2.5-k g \text { reduction } \\
\text { in gestational weight gain }\end{array}$ & $\begin{array}{l}\text { Control group: probability } \\
\text { of adverse maternal and } \\
\text { fetal outcomes }\end{array}$ & $\begin{array}{c}\text { Sample size required to } \\
\text { detect a } 30 \% \text { reduction } \\
\text { in adverse maternal and } \\
\text { fetal outcomes }\end{array}$ \\
\hline \multirow[t]{3}{*}{ BMI } & Obese & 7.5 & 300 & 0.30 & 770 \\
\hline & Overweight & 7.5 & 300 & 0.20 & 1,290 \\
\hline & Normal & 5.1 & 140 & 0.12 & 2,330 \\
\hline \multirow[t]{2}{*}{ Age } & $<20$ years & 7.12 & 270 & & \\
\hline & $\geq 20$ years & 5.87 & 184 & & \\
\hline \multirow[t]{3}{*}{ Ethnicity } & Caucasian & 3.4 & 64 & & \\
\hline & Asian & 3.8 & 78 & & \\
\hline & African & 5.1 & 140 & & \\
\hline \multirow[t]{2}{*}{ Parity } & $<1$ & 6.28 & 212 & & \\
\hline & $\geq 1$ & 6.68 & 238 & & \\
\hline \multirow[t]{2}{*}{ Risk factors like diabetes } & High risk & 6.81 & 248 & & \\
\hline & Low risk & 6.67 & 236 & & \\
\hline
\end{tabular}

level, the random effects to account for heterogeneity will be assumed normally distributed allowing us to estimate the average intervention effect and its confidence interval, and the between-study variance ('tau-squared'). To reveal the impact of heterogeneity more clearly, we will also calculate a 95\% prediction interval for the intervention effect when applied in an individual clinical setting [32].

\section{Examining heterogeneity and estimating intervention effects within each subgroup}

To consider the causes of heterogeneity and factors that may modify the intervention effect for each outcome, for each weight management intervention we will meet the primary objectives of our project by performing the pre-specified subgroup analyses by BMI, age; ethnicity, parity, risk status of medical comorbidities in pregnancy risk; and type of intervention. To obtain the summary intervention effects in each subgroup, we will use the same random-effects meta-analysis approach as described above. Subgroup analyses, if not carefully planned, can lead to misleading results e.g. due to the play of chance with multiple testing [32]. Thus caution will be used in the interpretation of the collective set of subgroup results, and adjustment for multiple testing will be considered.

It is important to calculate the difference in intervention effect between subgroups, to ascertain if any observed differences are due to chance. This will be undertaken by extending the one-stage meta-analysis framework to include treatment-covariate interaction terms, which provide the change in intervention effect for a 1-unit change in the covariate. In doing so, we will ensure that we estimate the pooled within-trial interaction of interest separately from the across-trial (meta-regression) interaction, as recommended because the former is the desired information as it is based solely on patient-level information $[33,34]$. Between-study heterogeneity in the within-trial treatment-covariate will also be measured, summarised and, if necessary, accounted for in the analysis. Continuous covariates, such as BMI and age, will be analysed on their continuous scale, rather than categorisation [35]. However, to translate the results clinically, after the analysis we will report the effect of the covariate-treatment interaction on the intervention effect at clinically relevant covariate values, such normal weight values, overweight values, and obese values, and those aged under or over 18 .

As a secondary analysis, we will evaluate the association between weight gain in pregnancy and adverse maternal and fetal outcomes in normal weight, overweight, and obese women. For each group separately and each outcome, we will fit a suitable regression model that accounts for clustering of patient within studies and quantifies how each 1-unit increase in weight gain changes the risk of a poor outcome. As the relationship is likely to be non-linear, we will consider non-linear trends between weight gain and outcome using fractional polynomial terms [35]. For each type of outcome, a suitable model will be used such as linear regression for continuous outcomes, or logistic regression for binary outcomes. The model will account for the clustering of patients within trials, and their treatment group allocation. Further, we will consider whether the association between weight gain and outcome interacts with whether a patient is in the intervention group or not. 


\section{Evaluation of potential prognostic factors for weight change in pregnancy}

In secondary analyses, we will also evaluate those variables that may have a prognostic effect on gestational weight gain including age, ethnicity, underlying medical conditions like diabetes, parity, type and duration of intervention, mental health, and socioeconomic status [36]. For all candidate prognostic factors (predictors), we will perform separate analyses in each BMI cohort (normal, overweight, and obese) and analyse on the whole meta-analysis database, adjusting again for the clustering of patients within studies and accounting for heterogeneity as necessary. To obtain adjusted prognostic factor results, multivariable models will be fitted including all variables of interest, to ascertain which have independent prognostic value.

\section{Network meta-analyses}

We will rank the interventions according to their effectiveness using a network meta-analysis approach [37]. Under the assumption that the sets of trials in each meta-analysis are comparable, an indirect comparison will be carried out by calculating the difference in treatment effect sizes for all interventions (to get say A vs B using A vs $\mathrm{C}$ minus $\mathrm{B}$ vs $\mathrm{C}$ ). Within-trial randomised comparisons of each study will be preserved. Our network meta-analyses will be undertaken in a frequentist framework using multivariate meta-analysis models within the STATA modules 'network' $[38,39]$, which allows within-study correlations (between pairs of effect estimates from the same study) and between-study correlations to be accounted for as necessary. The consistency assumption will also be examined in this framework, for example, by comparing the difference in direct and indirect effect estimates and comparing the fit of consistency and inconsistency models. We note that where indirect comparisons have been compared to direct comparisons, over 95\% concordance has been found [35,40]. Ranking will be achieved by assuming flat, uninformative prior distributions for all parameters, and thus assuming the multivariate normal sampling distribution of the pooled treatment effects is a posterior distribution with mean and variance equal to the frequentist estimates and variance-covariance matrix. Thus, approximate Bayesian inferences are then possible. One thousand draws will be made from the posterior distribution, and the treatments will be ordered according to the probability (across all draws) that they are the most effective on average.

\section{Exploration of sources of bias: unavailable data and publication bias}

We will explore the potential for, and possible impact of, both publication bias and unavailable data, according to recent guidelines [41]. For each analysis containing ten or more studies, the likelihood of publication bias will be investigated through the construction of contourenhanced funnel plots and appropriate statistical tests for 'small-study effects'; that is, the tendency for smaller studies to provide more positive findings.

In addition, for all studies where IPD were not provided to us, we will seek to extract suitable aggregate data from their study publications (such aggregate data has already been extracted from our previous HTA review). Where possible, we will then, using the two-step meta-analysis framework, combine the IPD trials with the aggregate data from other trials using suitable statistical methods to examine if conclusions change by the inclusion of additional trials [33,34]. If the inclusion of studies lacking IPD seems to have an important statistical or clinical impact, we will compare the characteristics of the studies with IPD and of those without to see if there are any key differences (such as in their quality, follow-up length, statistical methods). We recognise, however, that this approach is likely to only be achievable when examining the overall treatment effect, and our main IPD analyses of the subgroup effects are unlikely to be able to include any suitable aggregate data for subgroup effects from non-IPD studies (the very reason why we have sought IPD for meta-analysis).

\section{Health economic evaluation}

We will develop a decision analytic simulation model as a framework for conducting cost-effectiveness and cost-utility analyses and associated value of information analyses $[42,43]$. The economic evaluations will inform current treatment policy in this clinical area, whilst the value of information component will serve to highlight future research needs and agendas and inform possible future research funding decisions.

The main objective of the evaluation will be to determine the characteristics of the weight management intervention(s) that are most cost-effective. Hence, the range of options (in terms of duration, frequency and intensity) for which trial data exist will be investigated.

An incremental approach will be adopted with a focus on additional costs and gain in benefits associated with a move away from current practice to alternative treatment strategies. The cost-effectiveness component of the work will report results in terms of an incremental costeffectiveness ratio (ICER) of cost per unit of benefit gained, measured in appropriate clinical and economically relevant outcome measures.

Some limited quality of life data potentially suitable for use in a cost-utility framework are available from published sources [44,45], and so the economic evaluation will attempt additionally to present results in terms 
of incremental cost per quality-adjusted life year (QALY) gained.

The results will be presented using cost-effectiveness acceptability curves to reflect sampling variation and uncertainties in the appropriate threshold cost-effectiveness value. We shall also include a value of information analysis to quantify the total uncertainty in terms of the value of removing that uncertainty. In addition to this probabilistic sensitivity analysis on our base-case model, we shall include a range of alternative analyses to explore the robustness of these results to plausible variations in key assumptions and variations in the analytical methods used and to consider the broader issue of the generalisability of the results.

\section{Discussion}

The IPD meta-analysis will allow us to identify and subsequently target the interventions to those groups that show clear benefit with weight management in pregnancy. It has greater power to detect any differential treatment effect across groups as it can model individual risk status (prognostic factor values) across participants within trials and thus explain variability in outcomes at the patient-level [16]. In contrast, aggregate data metaanalysis can only model average risk status values across studies and thus only explain variation in summary outcomes at the study-level. Availability of IPD alleviates the need to use published results and is thus less likely to be affected by selective and biased reporting than an aggregate data meta-analysis. It also has the potential to assess longer follow-up and include more participants and more outcomes than reported in the original publication.

Weight gain in pregnancy varies with age, ethnicity, and parity. Pregnancy during adolescence may alter normal growth processes and increase the risk of the mothers becoming overweight or obese [46]. Adolescent mothers also retain more weight postpartum than mature control subjects [46]. Therefore, inclusion of a large number of pregnant adolescents may overestimate postpartum weight changes or the risk of becoming overweight and thus bias estimates for mature women. In the US, immigrant women are known to have less gestational weight gain but the same rate of complications in pregnancy compared to the domestic population [47]. Ethnic differences in the relationship between weight gain and complications need further investigation.

The trials identified in our previous HTA systematic review on diet and lifestyle interventions in pregnancy were powered to detect an overall treatment effect, but not to detect a subgroup effect. The costs and time to undertake a new trial for this purpose would be immense.
One of the key recommendations that arose from the study level meta-analysis of dietary and physical activity interventions in pregnancy was the need to synthesise patient level data to assess any differential effect of the benefits observed with interventions in various subgroups $[21,27]$. Such questions are difficult to answer using extracted results from trial publications, as patientlevel information is no longer available and subgroup effects ('treatment-covariate interactions') are rarely reported in sufficient detail. Furthermore, meta-regression examining the across-trial association between overall treatment effect and average patient characteristics (e.g. mean age) generally has low power to detect genuine subgroup effects and is also prone to study-level confounding $[33,48]$.

We have chosen composite maternal and fetal outcomes to assess the effects of interventions in pregnancy as it is difficult to identify one clinically important outcome. The components of the composite maternal and fetal outcomes were identified by Delphic survey of experts ensuring face validity of the components. Through our systematic review of randomised trials, we have shown that there is an association between change in the individual outcomes in the same direction and weight management interventions, thereby ensuring content validity of the chosen composite outcome measure [27].

Our collaborative group has provisional support so far to include over 9,000 women. In contrast, single trials in this field have so far included much smaller number of women, with a median number of 137 women (smallest $n=12$; largest $n=1,500$ ). Thus, there is over a 50 -fold increase in the sample size for our IPD project compared to the median number in the trials. We recognise that there is additional variability in an IPD meta-analysis due to clustering of patients within studies and heterogeneity in effects across studies. However, compared to a single trial that typically has 137 women, the provision of 9,000 patients within our IPD meta-analysis will dramatically improve upon singletrial research.

\section{Abbreviation}

BMI: body mass index; CDSR: Cochrane Database of Systematic Reviews; CENTRAL: Cochrane Central Register of Controlled Trials; DARE: Database of Abstracts of Reviews of Effects; HTA: Health Technology Assessment Database; ICER: incremental cost-effectiveness ratio; IOM: Institute of Medicine; IPD: individual patient data; i-WIP: International Weight Management in Pregnancy; MID: minimally important difference; NICE: National Institute for Health and Care Excellence; NHS: National Health Service; PHIAC: Public Health Interventions Advisory Committee; QALY: quality-adjusted life year; SD: standard deviation; SIGLE: Systems for Information in Grey Literature; UK: United Kingdom; US: United States; VOI: value of information; WHO: World Health Organization. 


\section{Authors' contributions}

AR was involved in the concept and the design of the study and planned and wrote the initial protocol. She also participated in face-to-face meeting and/or teleconferences to discuss protocol, design of the meta-analysis, the choice of outcome measures and analysis strategies. ST was involved in the concept and the design of the study, and planned and wrote the initial protocol. She also participated in face-to-face meetings and/or teleconferences to discuss protocol, design of the meta-analysis, the choice of outcome measures and analysis strategies. RR was involved in the concept and the design of the study, and wrote a significantly part of the protocol. He also participated in face-to-face meetings and/or teleconferences to discuss the protocol, design of the meta-analysis, the choice of outcome measures and analysis strategies. KK was involved in the concept and the design of the study, and contributed significantly to the planning and writing of the protocol. $\mathrm{He}$ also participated in face-to-face meetings and/or teleconferences to discuss the protocol, design of the meta-analysis, the choice of outcome measures and analysis strategies. BWM was involved in the concept and the design of the study, and contributed significantly to the planning and writing of the protocol. He also participated in face-to-face meetings and/or teleconferences to discuss the protocol, design of the meta-analysis, the choice of outcome measures and analysis strategies. ER was involved in the concept and the design of the study, and contributed significantly to the planning and writing of the protocol. She also participated in face-to-face meetings and/or teleconferences to discuss the protocol, design of the meta-analysis, the choice of outcome measures and analysis strategies. MvP contributed significantly to the planning and writing of the protocol. She also participated in face-to-face meetings to discuss the protocol, design of the meta-analysis, the choice of outcome measures and analysis strategies. GR contributed significantly to the planning and writing of the protocol. He also participated in face-to-face meetings and/or teleconferences to discuss the protocol, design of the meta-analysis, the choice of outcome measures and analysis strategies. SK contributed significantly to the planning and writing of the protocol. She also participated in face-to-face meetings and/or teleconferences to discuss the protocol, design of the meta-analysis, the choice of outcome measures and analysis strategies. CdG was involved in the concept and the design of the study, and contributed significantly to the planning and writing of the protocol. SY contributed significantly to the planning and writing of the protocol. EM contributed significantly to the planning and writing of the protocol. She also participated in face-to-face meetings and/or teleconferences to discuss the protocol, design of the meta-analysis, the choice of outcome measures and analysis strategies. FM contributed significantly to the planning and writing of the protocol. She also participated in face-to-face meetings and/or teleconferences to discuss the protocol, design of the meta-analysis, the choice of outcome measures and analysis strategies. LP was contributed significantly to the planning and writing of the protocol. She also participated in face-to-face meetings and/or teleconferences to discuss the protocol, design of the meta-analysis, the choice of outcome measures and analysis strategies. TR contributed significantly to the planning and writing of the protocol. She also participated in face-to-face meetings and/or teleconferences to discuss the protocol, design of the meta-analysis, the choice of outcome measures and analysis strategies. AC contributed significantly to the planning and writing of the protocol. He also participated in face-to-face meetings and/or teleconferences to discuss the protocol, design of the meta-analysis, the choice of outcome measures and analysis strategies. All authors critically reviewed the subsequent versions of the manuscript and approved the final manuscript.

\section{Acknowledgements}

We would like to acknowledge all researchers and research nurses as well as the staff of the participating centres in the studies contributing to this individual patient data meta-analysis.

\section{Funding}

This study was funded by the National Institute for Health Research (NIHR) HTA (Health Technology Assessment) UK programme 12/01.

\section{i-WIP (International Weight Management in Pregnancy)}

Collaborative Group

The i-WIP collaborators are shown in Table 5.

Table 5 i-WIP collaborators

\begin{tabular}{|c|c|c|c|c|}
\hline Trial & Year & Corresponding author & Country & Affiliation \\
\hline Althuizen & 2012 & Mireille van Poppel & Amsterdam, Netherlands & $\begin{array}{l}\text { Department of Public and Occupational } \\
\text { Health, EMGO + Institute for Health and Care } \\
\text { Research, VU University Medical Center, } \\
\text { Amsterdam }\end{array}$ \\
\hline Barakat & 2009, 2011, 2013 & Ruben Barakat Carballo & Madrid, Spain & $\begin{array}{l}\text { Facultad de Ciencias de la Actividad Fı'sica y } \\
\text { del Deporte-INEF, Universidad Polite'cnica de } \\
\text { Madrid }\end{array}$ \\
\hline
\end{tabular}

Bogaerts $2012 \quad$ Annick Bogaerts Leuven, Belgium

Division of Mother and Child, Department of Obstetrics and Gynaecology, Limburg Catholic University College Hasselt and University Hospitals KU Leuven

Cavalcante $2009 \quad$ Jose G Cecatti Sao Paulo, Brazil

Clapp 1997, $2000 \quad$ Beth Lopez Cleveland, USA

Obstetrics and Gynecology, School of Medical Sciences, University of Campinas (UNICAMP)

Departments of Reproductive Biology and Obstetrics and Gynecology and the Schwartz Center for Metabolism and Nutrition, Case Western Reserve University and MetroHealth Medical Center

$\begin{array}{llll}\text { Dodd } & 2014 & \text { Jodie Dodd } & \text { Adelaide, Australia } \\ \text { El Beltagy } & 2013 & \text { Nermeen El Beltagy } & \text { Alexandria, Egypt } \\ \text { Guelinckx } & 2010 & \text { Roland Devlieger } & \text { Leuven, Belgium }\end{array}$

Discipline of Obstetrics and Gynaecology, School of Paediatrics and Reproductive Health, The University of Adelaide

Department of Obstetrics and Gynecology, Alexandria University

Division of Mother and Child, Department of Obstetrics and Gynaecology, University Hospitals KU Leuven 
Table 5 i-WIP collaborators (Continued)

\begin{tabular}{|c|c|c|c|c|}
\hline Haakstad & 2011 & Lene Haakstad & Oslo, Norway & $\begin{array}{l}\text { Norwegian School of Sport Sciences, } \\
\text { Department of Sports Medicine }\end{array}$ \\
\hline Hui & 2006, 2011 & Gary Shen & Manitoba, Canada & $\begin{array}{l}\text { Department of Internal Medicine, University of } \\
\text { Manitoba, Winnipeg }\end{array}$ \\
\hline Jeffries & 2009 & Alexis Shub & Melbourne, Australia & $\begin{array}{l}\text { Department of Obstetrics and Gynaecology, } \\
\text { University of Melbourne }\end{array}$ \\
\hline Khaledan & 2010 & Narges Motahari & Babolsar, Iran & $\begin{array}{l}\text { Dept. Physiology, School of Physical } \\
\text { Education, Mazandaran University }\end{array}$ \\
\hline Khoury & 2005 & Janette Khoury & Oslo, Norway & $\begin{array}{l}\text { Department of Obstetrics and Gynecology, } \\
\text { National University Hospital }\end{array}$ \\
\hline Luoto & 2011 & Riitta Luoto & Helsinki, Finland & UKK Institute for Health Promotion Research \\
\hline Nashimento & 2011 & Jose G Cecatti, PhD MD & Sao Paulo, Brazil & $\begin{array}{l}\text { Department of Obstetrics and Gynecology, } \\
\text { School of Medical Sciences, University of } \\
\text { Campinas (UNICAMP) }\end{array}$ \\
\hline Ong & 2009 & Kym Guelfi & Crawley, Australia & $\begin{array}{l}\text { School of Sport Science, Exercise and Health, } \\
\text { The University of Western Australia }\end{array}$ \\
\hline Oostdam & 2009 & Mireille van Poppel & Amsterdam, Netherlands & $\begin{array}{l}\text { Department of Public and Occupational } \\
\text { Health, EMGO + Institute for Health and Care } \\
\text { Research, VU University Medical Center, } \\
\text { Amsterdam }\end{array}$ \\
\hline Petrella & 2013 & Fabio Facchinetti & Modena, Italy & $\begin{array}{l}\text { Mother-Infant Department, University of } \\
\text { Modena and Reggio Emilia }\end{array}$ \\
\hline Phelan & 2011 & Suzanne Phelan & San Luis Obispo, USA & $\begin{array}{l}\text { Kinesiology Department, California Polytechnic } \\
\text { State University }\end{array}$ \\
\hline Poston & 2013 & Lucilla Poston & London, UK & $\begin{array}{l}\text { King's College London, Division of Women's } \\
\text { Health, Women's Health Academic Centre }\end{array}$ \\
\hline Prevedel & 2003 & Tânia T Scudeller Prevedel & Sao Paulo, Brazil & $\begin{array}{l}\text { Department of Obstetrics, Faculty of Medicine, } \\
\text { Botucatu }\end{array}$ \\
\hline Rauh & 2013 & Kathrin Rauh & Munich, Germany & $\begin{array}{l}\text { Else Kroener-Fresenius-Center for Nutritional } \\
\text { Medicine, Chair of Nutritional Medicine, } \\
\text { Technische Universität München }\end{array}$ \\
\hline Renault & 2013 & Kristina Renault & Copenhagen, Denmark & $\begin{array}{l}\text { Departments of Obstetrics and Gynecology, } \\
\text { Hvidovre Hospital, University of Copenhagen }\end{array}$ \\
\hline Sagedal & 2014 & Linda Reme Sagedal & Kristiansand, Norway & $\begin{array}{l}\text { Department of Obstetrics and Gynecology, } \\
\text { Sorlandet Hospital }\end{array}$ \\
\hline Stafne & 2012 & $\begin{array}{l}\text { Signe Nilssen Stafne and } \\
\text { Siv Mørkved }\end{array}$ & Trondheim, Norway & $\begin{array}{l}\text { Department of Public Health and General } \\
\text { Practice, Faculty of Medicine, Norwegian } \\
\text { University of Science and Technology }\end{array}$ \\
\hline Vesco & 2013 & Kimberly Vesco & Portland, USA & Center for Health Research, Portland \\
\hline Vinter & 2011 & Christina Vinter & Odense, Denmark & $\begin{array}{l}\text { Department of Gynecology and Obstetrics, } \\
\text { Odense University Hospital }\end{array}$ \\
\hline Vitolo & 2011 & Vitolo & Porto Alegre, Brazil & $\begin{array}{l}\text { Department of Nutrition and the Graduate } \\
\text { Program in Health Sciences, Federal University } \\
\text { of Health Sciences of Porto Alegre }\end{array}$ \\
\hline Walsh & 2012 & Fionnuala M McAuliffe & Dublin, Ireland & $\begin{array}{l}\text { UCD Obstetrics and Gynaecology, School of } \\
\text { Medicine and Medical Science, University } \\
\text { College Dublin, National Maternity Hospital, } \\
\text { Dublin, Ireland }\end{array}$ \\
\hline Wolff & 2008 & Arne Astrup & Copenhagen, Denmark & $\begin{array}{l}\text { Department of Human Nutrition, Faculty of } \\
\text { Life Science, Copenhagen University }\end{array}$ \\
\hline Yeo & 2000 and 2012 & Seonae Yeo & Chapel Hill, North Carolina, USA & $\begin{array}{l}\text { School of Nursing, University of North Carolina } \\
\text { at Chapel Hill }\end{array}$ \\
\hline
\end{tabular}




\section{Author details}

${ }^{1}$ Department of Obstetrics and Gynecology, Academic Medical Centre, Amsterdam, The Netherlands. ²Department of Obstetrics and Gynaecology, Faculty of Medicine, VU University Medical Center, Amsterdam, The Netherlands. 'Women's Health Research Unit, Barts and The London School of Medicine and Dentistry, Queen Mary University of London, London, UK ${ }^{4}$ Department of Public and Occupational Health, EMGO + Institute for Health and Care Research, VU University Medical Center, Amsterdam, The Netherlands. ${ }^{5}$ Multidisciplinary Evidence Synthesis Hub (mEsh), Barts and The London School of Medicine and Dentistry, Queen Mary University of London, London, UK. ${ }^{6}$ School of Nursing, University of North Carolina at Chapel Hill, Chapel Hill, NC, USA. 7 Section of Women's Mental Health, Health Service and Population Research Department, Institute of Psychiatry, King's College London, London, UK. ${ }^{8}$ School of Medicine \& Medical Science, UCD Institute of Food and Health, Dublin, Ireland. 'Division of Women's Health, Women's Health Academic Centre, King's College London, St. Thomas' Hospital, London, UK. ${ }^{10}$ Health Economics Unit, School of Health and Population Sciences, College of Medical and Dental Sciences, University of Birmingham, Birmingham, UK. ${ }^{11}$ School of Health and Population Sciences, College of Medical and Dental Sciences, University of Birmingham, Edgbaston, Birmingham B15 2TT, UK. ${ }^{12}$ School of Clinical and Experimental Medicine, College of Medical and Dental Sciences, University of Birmingham, Birmingham, UK. ${ }^{13}$ School of Paediatrics and Reproductive Health, Robinson Institute, University of Adelaide, Adelaide, Australia.

Received: 9 July 2014 Accepted: 3 October 2014

Published: 4 November 2014

\section{References}

1. Cedergren M: Effects of gestational weight gain and body mass index on obstetric outcome in Sweden. Int J Gynaecol Obstet 2006, 93:269-274.

2. Devader SR, Neeley HL, Myles TD, Leet TL: Evaluation of gestational weight gain guidelines for women with normal prepregnancy body mass index. Obstet Gynecol 2007, 110:745-751

3. Hedderson MM, Gunderson EP, Ferrara A: Gestational weight gain and risk of gestational diabetes mellitus. Obstet Gynecol 2010, 115:597-604.

4. Olson CM: Achieving a healthy weight gain during pregnancy. Annu Rev Nutr 2008, 28:411-423.

5. Rasmussen T, Stene LC, Samuelsen SO, Cinek O, Wetlesen T, Torjesen PA Rønningen KS: Maternal BMI before pregnancy, maternal weight gain during pregnancy, and risk of persistent positivity for multiple diabetesassociated autoantibodies in children with the high-risk HLA genotype: the MIDIA study. Diabetes Care 2009, 32:1904-1906.

6. Siega-Riz AM, Siega-Riz AM, Laraia B: The implications of maternal overweight and obesity on the course of pregnancy and birth outcomes. Matern Child Health J 2006, 10:S153-S156.

7. Thorsdottir I, Torfadottir JE, Birgisdottir BE, Geirsson RT: Weight gain in women of normal weight before pregnancy: complications in pregnancy or delivery and birth outcome. Obstet Gynecol 2002, 99:799-806.

8. Zhang X, Decker A, Platt RW, Kramer MS: How big is too big? The perinatal consequences of fetal macrosomia. Am J Obstet Gynecol 2008, 198:517-516.

9. Oken E, Taveras EM, Kleinman KP, Rich-Edwards JW, Gillman MW: Gestational weight gain and child adiposity at age 3 years. Am J Obstet Gynecol 2007, 196:322-328.

10. Sharma AJ, Cogswell ME, Grummer Strawn LM: The association between pregnancy weight gain and childhood overweight is modified by mother's pre pregnancy BMI. Pediatr Res 2005, 58:1038.

11. NIDDK Weight Control Information Network. US Department of Health and Human Services $\mathrm{NloH}$ : Healthy eating and physical activity across your life span: fit for two: tips for pregnancy: NIDDK Weight Control Information Network. 2002. NIH Publication No 02-5130.

12. Confidential Enquiry into Maternal and Child Health: Saving mothers' lives: reviewing maternal deaths to make motherhood safer. The seventh report of the confidential enquiries into maternal deaths in the United Kingdom. London: 2007.

13. Dodd JM, Crowther CA, Robinson JS: Dietary and lifestyle interventions to limit weight gain during pregnancy for obese or overweight women: A systematic review. Acta Obstet Gynecol Scand 2008, 87:702-706.

14. Galtier Dereure F, Boegner C, Bringer J: Obesity and pregnancy: complications and cost. Am J Clin Nutr 2000, 71:1242S-1248S.
15. Heslehurst N, Rankin J, Wilkinson JR, Summerbell CD: A nationally representative study of maternal obesity in England, UK: trends in incidence and demographic inequalities in 619323 births, 1989-2007. Int J Obes (Lond) 2010, 34:420-428.

16. Linné $Y$, Dye $L$, Barkeling B, Rössner S: Long-term weight development in women: a 15-year follow-up of the effects of pregnancy. Obes Res 2004, 12:1166-1178.

17. Rooney BL, Schauberger CW: Excess pregnancy weight gain and longterm obesity: one decade later. Obstet Gynecol 2002, 100:245-252.

18. Department of health: Department of Health. 2013 [http://www.dh.gov.uk/ health/category/policy-areas/public-health/obesity-healthy-living]

19. UK Government Web Archive 2013. [http://webarchive.nationalarchives.gov. uk/+/www.dh.gov.uk/en/Publichealth/Obesity/DH_078098]

20. Jackson RA, Stotland NE, Caughey AB, Gerbert B: Improving diet and exercise in pregnancy with video doctor counseling: a randomized trial. Patient Educ Couns 2011, 83:203-209.

21. Thangaratinam S, Rogozinska E, Jolly K, Glinkowski S, Roseboom T, Tomlinson JW, Kunz R, Mol BW, Coomarasamy A, Khan KS: Effects of interventions in pregnancy on maternal weight and obstetric outcomes: a meta-analysis of randomised evidence. BMJ 2012, 344:e2088.

22. National Institute for Health and Care Excellence: Recommendation ID PH27/3 2013. [http://www.nice.org.uk]

23. Riley RD, Lambert PC, Abo-Zaid G: Meta-analysis of individual participant data: rationale, conduct, and reporting. BMJ 2010, 340:c221.

24. Montori VM, Permanyer-Miralda G, Ferreira-González I, Busse JW Pacheco-Huergo V, Bryant D, Alonso J, Akl EA, Domingo-Salvany A, Mills E, Wu P, Schünemann HJ, Jaeschke R, Guyatt GH: Validity of composite end points in clinical trials. BMJ 2005, 330:594-596.

25. National Health Service 2013. [http://www.nice.org.uk/]

26. National Institute for Health and Clinical Excellence: NICE public health guidance 27: dietary interventions and physical activity interventions for weight management before, during and after pregnancy. National Institute for Health and Clinical Excellence 2010.

27. Thangaratinam S, Rogozinska E, Jolly K, Glinkowski S, Duda W, Borowiack E, Roseboom T, Tomlinson J, Walczak J, Kunz R, Mol BW, Coomarasamy A, Khan KS: Interventions to reduce or prevent obesity in pregnant women: a systematic review. Health Technol Assess 2012, 16:1-192.

28. Glasziou P, Chalmers I, Altman DG, Bastian H, Boutron I, Brice A, Jamtvedt G, Farmer A, Ghersi D, Groves T, Heneghan C, Hill S, Lewin S, Michie S, Perera R, Pomeroy V, Tilson J, Shepperd S, Williams JW: Taking healthcare interventions from trial to practice. BMJ 2010, 341:c3852.

29. Guyatt GH, Oxman AD, Kunz R, Vist GE, Falck-Ytter Y, Schunemann HJ: What is "quality of evidence" and why is it important to clinicians? BMJ 2008, 336:995-998.

30. Debray TP, Moons KG, Abo-Zaid GM, Koffijberg H, Riley RD: Individual participant data meta-analysis for a binary outcome: one-stage or twostage? PLoS One 2013, 8:e60650.

31. Vickers AJ, Altman DG: Statistics notes: analysing controlled trials with baseline and follow up measurements. BMJ 2001, 323:1123-1124.

32. Riley RD, Higgins JP, Deeks JJ: The interpretation of random-effects meta-analysis. BMJ 2011, 342:d549.

33. Riley RD, Lambert PC, Staessen JA, Wang J, Gueyffier F, Thijs L, Boutitie F: Meta-analysis of continuous outcomes combining individual patient data and aggregate data. Stat Med 2008, 27:1870-1893.

34. Riley RD, Steyerberg EW: Meta-analysis of a binary outcome using individual participant data and aggregate data. J Res Syn Meth 2010, 1:2-9.

35. Royston $P$, Sauerbrei W: A new approach to modelling interactions between treatment and continuous covariates in clinical trials by using fractional polynomials. Stat Med 2004, 23:2509-2525.

36. Riley RD, Hayden JA, Steyerberg EW, Moons KG, Abrams K, Kyzas PA Malats N, Briggs A, Schroter S, Altman DG, Hemingway H, PROGRESS Group: Prognosis research strategy (PROGRESS) 2: prognostic factor research. PLoS Med 2013, 10:e1001380

37. Ades AE, Caldwell DM, Reken S, Welton NJ, Sutton AJ, Dias S: Evidence synthesis for decision making 7: a reviewer's checklist. Med Decis Making 2013, 33:679-691.

38. White IR, Barrett JK, Jackson D, Higgins JPT: Consistency and inconsistency in network meta-analysis: model estimation using multivariate metaregression. Res Synth Method 2012, 2012(3):111-125.

39. White IR: Network Meta-Analysis Modules in STATA. [http://www.mrc-bsu. cam.ac.uk/software/stata-software/] 
40. Glenny AM, Altman DG, Song F, Sakarovitch C, Deeks JJ, D'Amico R, Bradburn M, Eastwood AJ, International Stroke Trial Collaborative Group: Indirect comparisons of competing interventions. Health Technol Assess 2005, 9:iii-iv.

41. Ahmed I, Sutton AJ, Riley RD: Assessment of publication bias, selection bias, and unavailable data in meta-analyses using individual participant data: a database survey. BMJ 2012, 344:d7762.

42. Claxton $\mathrm{K}$, Thompson KM: A dynamic programming approach to the efficient design of clinical trials. J Health Econ 2001, 20:797-822.

43. Felli JC, Hazen GB: Sensitivity analysis and the expected value of perfect information. Med Decis Making 1998, 18:95-109.

44. Tappenden P, McCabe C, Chilcott J, Simpson E, Nixon R, Madan J, Fisk JD, Brown M: Cost-effectiveness of disease-modifying therapies in the management of multiple sclerosis for the Medicare population. Value Health 2009, 12:657-665.

45. Gomez JA, Tirado JC, Navarro Rojas AA, Castrejon Alba MM, Topachevskyi O: Cost-effectiveness and cost utility analysis of three pneumococcal conjugate vaccines in children of Peru. BMC Public Health 2013, 13:1025.

46. Gunderson EP, Abrams B: Epidemiology of gestational weight gain and body weight changes after pregnancy. Epidemiol Rev 2000, 22:261-274.

47. Rasmussen KM, Yatkine AL: Weight gain during pregnancy: re-examining the guidelines. Committee to Reexamine Institute of Medicine Pregnancy Weight Guidelines 2009

48. Lambert PC, Sutton RJ, Abrams KR, Jones DR: A comparison of summary patient-level covariates in meta-regression with individual patient data meta-analysis. Clin Epidemiol 2002, 55:86-94.

doi:10.1186/2046-4053-3-131

Cite this article as: Ruifrok et al:: Study protocol: differential effects of diet and physical activity based interventions in pregnancy on maternal and fetal outcomes-individual patient data (IPD) meta-analysis and health economic evaluation. Systematic Reviews 2014 3:131.

\section{Submit your next manuscript to BioMed Central and take full advantage of:}

- Convenient online submission

- Thorough peer review

- No space constraints or color figure charges

- Immediate publication on acceptance

- Inclusion in PubMed, CAS, Scopus and Google Scholar

- Research which is freely available for redistribution 